\title{
Childhood-onset spasticity with hyperglycinemia
}

INSERM

\section{Source}

INSERM. (1999). Orphanet: an online rare disease and orphan drug data base. Childhoodonset spasticity with hyperg/ycinemia. ORPHA:401866

Childhood-onset spasticity with hyperglycinemia is a rare neurometabolic disease characterized by a childhood onset of progressive spastic ataxia associated with gait disturbances, hyperreflexia, extensor plantar responses and non-ketotic hyperglycinemia typically revealed by biochemical analysis. Additional signs of upper extremity spasticity, dysarthria, learning difficulties, poor concentration, nystagmus, optic atrophy and reduced visual acuity may also be associated. 